\title{
CHOROIDAL ABNORMALITIES IN BIRDSHOT CHORIORETINOPATHY: AN INDOCYANINE GREEN ANGIOGRAPHY STUDY
}

\author{
L. J. HOWE ${ }^{1}$, M. R. STANFORD ${ }^{2}$, E. M. GRAHAM ${ }^{2}$ and J. MARSHALL ${ }^{1}$ \\ London
}

\begin{abstract}
SUMMARY
Birdshot chorioretinopathy is a rare inflammatory disorder with an insidious onset that can slowly progress to severe visual loss. The pathogenesis is unknown. This study used indocyanine green (ICG) angiography to investigate the degree of choroidal vascular involvement with progression of disease and to determine the nature of the birdshot lesions. Seven patients with birdshot chorioretinopathy had ICG angiography performed with a scanning laser ophthalmoscope at various stages of clinical disease. Results were compared with fluorescein fundal angiography (FFA). All large choroidal vessels appeared normal. The birdshot lesions were demonstrated with ICG but not with FFA and were represented by dark areas on ICG angiography. Typically these areas were bordered by large or medium-sized choroidal vessels and their appearance suggested small choroidal vessel hypoperfusion. In disease of recent onset, some lesions masked fluorescence from large underlying choroidal vessels possibly due to inflammatory choroidal infiltrates. In long-standing disease, the choroidal angioarchitecture was relatively normal within the birdshot lesions. This study of birdshot chorioretinopathy demonstrates abnormalities in the small choroidal vessels within the birdshot lesions. ICG angiography detects the birdshot lesions more readily than FFA and may be of benefit in assessing disease activity.
\end{abstract}

Birdshot chorioretinopathy was first characterised as a distinct clinical entity by Ryan and Maumenee in $1980{ }^{1}$ They chose a purely descriptive term for this disease as the pathogenesis was unknown and, to date, the pathogenesis remains speculative. The clinical picture in combination with investigative results suggests a $\mathrm{T}$ cell-mediated inflammatory

From: ${ }^{1}$ Department of Ophthalmology, UMDS, and ${ }^{2}$ The Medical Eye Unit, St Thomas' Hospital, London, UK.

Correspondence to: Lucy Howe, FRCOphth, The Western Eye Hospital, Marylebone Road, London NW1 5 YE, UK. vasculopathy. Incomplete understanding of the aetiology of birdshot chorioretinopathy makes it difficult to devise rational treatment regimes and may be reflected by the poor visual prognosis in longstanding disease. ${ }^{2,3}$

Fluorescein angiographic studies of birdshot chorioretinopathy demonstrate frequent retinal vascular abnormalities of macular oedema and venous leakage. ${ }^{1,2,4,5}$ The birdshot lesions themselves, however, are associated with inconsistent fluorescein angiographic findings. There is a reported tendency for lesions of relatively recent onset to mask in the early phase of the angiogram and become fluorescent in the late phase, ${ }^{2,6,7}$ but this does not occur in all individuals or even in all lesions in the same individual. Frequently the birdshot lesions are not demonstrated at all despite the striking fundal picture. These angiographic findings are in keeping with the ophthalmoscopic appearance, which suggests that the lesions are located below the retinal pigment epithelium in the choroid. The choroidal vasculature can now be readily imaged using indocyanine green (ICG) as the contrast medium visualised with a specially adapted fundus camera ${ }^{8}$ or a scanning laser ophthalmoscope. ${ }^{9}$ This study was undertaken to examine the choroid in patients with birdshot chorioretinopathy with ICG angiography to determine the nature of the birdshot lesions and the degree of choroidal vascular involvement with progression of disease.

\section{PATIENTS AND METHODS}

Patients were recruited from the specialist uveitis clinics of St Thomas' Hospital, London. The study had hospital ethics committee approval and informed written consent was obtained from all patients prior to inclusion in the study. The diagnosis of birdshot chorioretinopathy was made on the basis of the original criteria outlined by Ryan and Maumenee. ${ }^{1}$ Additionally, any patients with clinical or laboratory 
Table I. Summary of patient characteristics, disease duration and visual acuities

\begin{tabular}{|c|c|c|c|c|c|c|}
\hline \multirow{2}{*}{$\begin{array}{l}\text { Patient } \\
\text { no. }\end{array}$} & \multirow[b]{2}{*}{ Sex } & \multirow{2}{*}{$\begin{array}{l}\text { Age } \\
\text { (years) }\end{array}$} & \multirow[b]{2}{*}{ HLA type } & \multirow{2}{*}{$\begin{array}{c}\text { Disease duration at time } \\
\text { of angiography }\end{array}$} & \multicolumn{2}{|c|}{ Visual acuity } \\
\hline & & & & & OD & OS \\
\hline 1 & Female & 42 & A29 & $\begin{array}{l}\text { (a) } 6 \text { months } \\
\text { (b) } 10 \text { months }\end{array}$ & $\begin{array}{l}\text { (a) } 6 / 5 \\
\text { (b) } 6 / 5\end{array}$ & $\begin{array}{l}6 / 6 \\
6 / 5\end{array}$ \\
\hline 2 & Male & 58 & A29 & $\begin{array}{l}\text { (a) } 15 \text { months } \\
\text { (b) } 20 \text { months }\end{array}$ & $\begin{array}{l}\text { (a) } 6 / 6 \\
\text { (b) } 6 / 6\end{array}$ & $\begin{array}{l}6 / 9 \\
6 / 12\end{array}$ \\
\hline 3 & Male & 61 & A29 & $\begin{array}{l}\text { (a) } 2 \text { years } \\
\text { (b) } 3 \text { years }\end{array}$ & $\begin{array}{l}\text { (a) } 6 / 18 \\
\text { (b) } 6 / 18\end{array}$ & $\begin{array}{l}\mathrm{HM} \\
\mathrm{HM}\end{array}$ \\
\hline $\begin{array}{l}4 \\
5\end{array}$ & $\begin{array}{l}\text { Male } \\
\text { Male }\end{array}$ & $\begin{array}{l}57 \\
60\end{array}$ & $\begin{array}{l}\text { A29 } \\
\text { A29 }\end{array}$ & 3 years & CF & $\begin{array}{l}6 / 60 \\
6 / 18\end{array}$ \\
\hline $\begin{array}{l}5 \\
6\end{array}$ & $\begin{array}{l}\text { Male } \\
\text { Female }\end{array}$ & $\begin{array}{l}60 \\
58\end{array}$ & $\begin{array}{c}\text { A29 } \\
\text { A29, B27 }\end{array}$ & $\begin{array}{l}4 \text { years } \\
5 \text { years }\end{array}$ & $\begin{array}{l}6 / 12 \\
6 / 12\end{array}$ & $\begin{array}{l}6 / 18 \\
6 / 12\end{array}$ \\
\hline 7 & Male & 54 & A 29 & 6 years & $6 / 60$ & $\mathrm{CF}$ \\
\hline
\end{tabular}

(a), at time of first angiogram; (b), at time of second angiogram; CF, counting fingers; HM, hand movements.

evidence of sarcoidosis were excluded as sarcoidosis can present with an identical clinical picture. ${ }^{10}$ Any patients with known iodine allergy were also excluded as the commercial preparation of ICG used contains iodine. All patients were tissue-typed. Full ophthalmic examination was followed by colour fundus photographs. Fluorescein angiography was performed with either a fundus camera (Kowa Prol, Tokyo, Japan) or scanning laser ophthalmoscope (model 101, Rodenstock, Munich, Germany) using the argon laser. ICG angiography was performed using $50 \mathrm{mg}$ ICG (Cardiogreen, Paesel and Loeri, Frankfurt, Germany) injected intravenously. All the ICG angiograms were performed with a Rodenstock scanning laser ophthalmoscope using the diode laser and images recorded on U-matic video tape. Colour photography and both types of angiography examined both the posterior poles and peripheral fundus.

\section{RESULTS}

Seven patients with birdshot chorioretinopathy were recruited into the study ( 5 men, 2 women); the patient characteristics are summarised in Table I. The mean age was 56 years (range 42-61 years). Mean disease duration at time of angiography was 2.7 years (range 6 months to 6 years). All patients had the tissue-type HLA A29 and one was also HLA B27. Three patients had angiography performed on two separate occasions.

The Snellen visual acuities at the time of angiography are given in Table I. All patients had white eyes with minimal or no anterior chamber inflammation and some vitreous inflammatory activity. Six patients had bilateral, symmetrical birdshot lesions often most pronounced in the inferonasal quadrant. The seventh patient (patient 4) had birdshot lesions in one eye while the second eye had old laser scars after fundal photocoagulation for repeated vitreous haemorrhages.

Fluorescein fundal angiography (FFA) findings are summarised in Table II. FFA failed to demonstrate the birdshot lesions in all patients (Fig. 5). Fluorescein leakage from retinal capillaries, veins and the optic disc was common. Only one patient (patient 7),

Table II. Fluorescein and indocyanine green angiography findings

\begin{tabular}{|c|c|c|}
\hline $\begin{array}{l}\text { Patient } \\
\text { no. }\end{array}$ & Fluorescein angiography findings ${ }^{\mathrm{a}}$ & ICG angiography findings ${ }^{\mathrm{b}}$ \\
\hline 1 & $\begin{array}{l}\text { (a) Dye leak from discs and RV bilaterally } \\
\text { (b) Findings unchanged }\end{array}$ & $\begin{array}{l}\text { (a) Few hypofluorescent areas masked fluorescence from } \\
\text { underlying choroidal vessels } \\
\text { (b) Findings unchanged }\end{array}$ \\
\hline 2 & $\begin{array}{l}\text { (a) Dye leak from RV bilaterally } \\
\text { (b) Dye leak from RV bilaterally. Small amount of late } \\
\text { capillary leak at left macula }\end{array}$ & $\begin{array}{l}\text { (a) Few hypofluorescent areas masked fluorescence from } \\
\text { underlying choroidal vessels. One lesion leaked ICG } \\
\text { (b) No leakage of ICG. Findings otherwise unchanged }\end{array}$ \\
\hline 3 & $\begin{array}{l}\text { (a) Angiogram not performed } \\
\text { (b) Small amount of late leak from RV. Diffuse RPE } \\
\text { irregularity }\end{array}$ & $\begin{array}{l}\text { (a) Angiographic findings of BL not as pronounced as clinical } \\
\text { appearance } \\
\text { (b) Unchanged }\end{array}$ \\
\hline 4 & Dye leak from neovascularisation. No retinal ischaemia & $\begin{array}{l}\text { Angiographic appearance of BL not as pronounced as clinical } \\
\text { appearance }\end{array}$ \\
\hline 5 & Bilateral late dye leak at maculae & $\begin{array}{l}\text { Angiographic appearance of BL not as pronounced as clinical } \\
\text { appearance }\end{array}$ \\
\hline 6 & Bilateral diffuse retinal capillary dye leak & $\begin{array}{l}\text { Angiographic appearance of BL not as pronounced as clinical } \\
\text { appearance }\end{array}$ \\
\hline 7 & $\begin{array}{l}\text { No dye leak. Irregular RPE at maculae consistent with } \\
\text { previous CMO }\end{array}$ & $\begin{array}{l}\text { Angiographic appearance of BL not as pronounced as clinical } \\
\text { appearance }\end{array}$ \\
\hline
\end{tabular}

(a), at time of first angiogram; (b), at time of second angiogram; BL, birdshot lesions; RV, retinal veins; CMO, cystoid maculár oedema; RPE, retinal pigment epithelium.

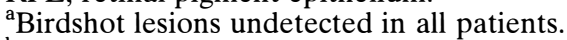

${ }^{\mathrm{b}}$ Birdshot lesions corresponded to hypofluorescent areas in all patients. No ICG leak from optic discs or RV. 


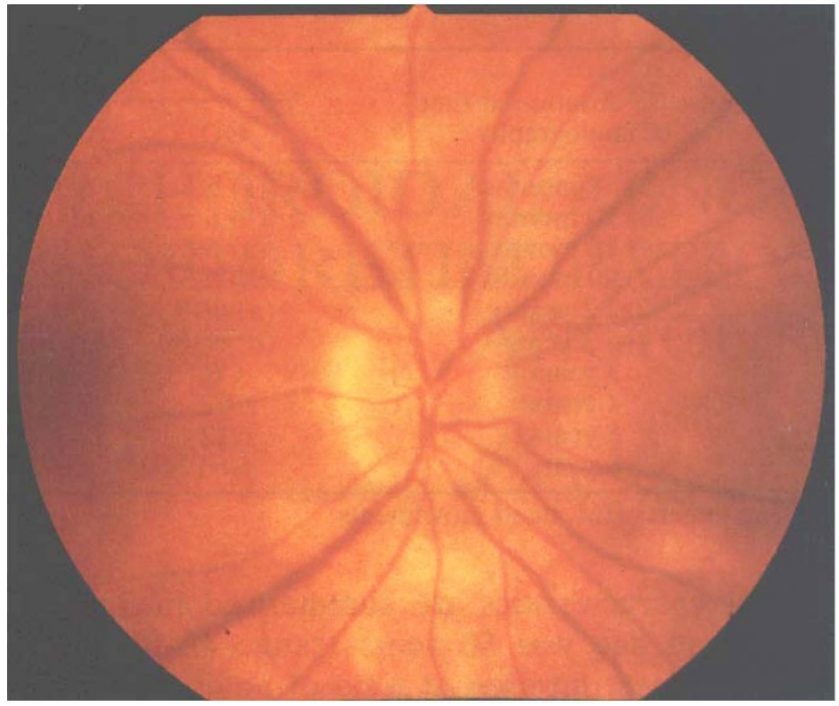

Fig. 1. Patient 2 (disease duration 15 months). Colour photograph of right fundus showing yellow-orange birdshot lesions.

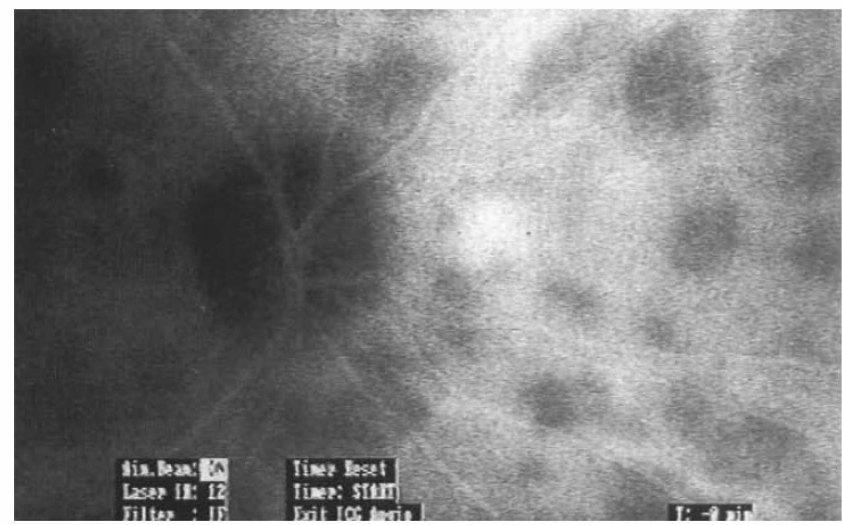

Fig. 3. Patient 2. Later phase (8 minutes) ICG angiogram of the same area as Fig. 1 showing persistent hypofluorescent areas. There is also increased leakage of ICG from the area just nasal to the optic disc.

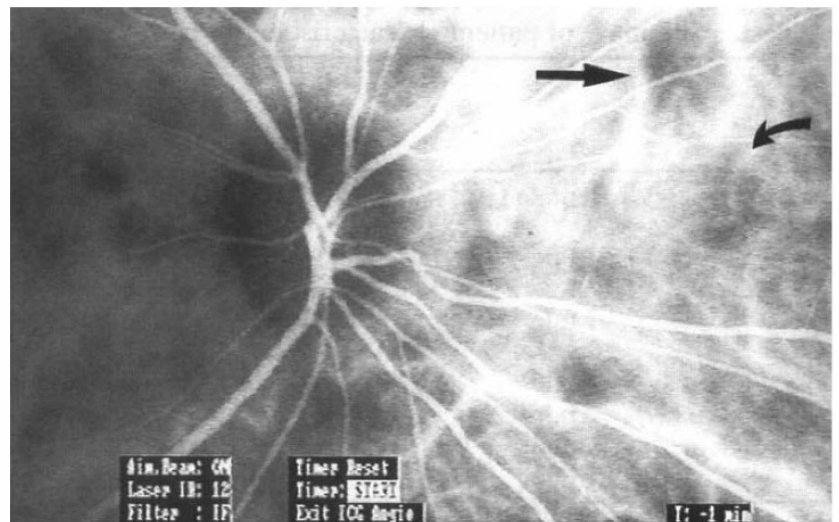

Fig. 2. Patient 2. Early phase (1 minute) indocyanine green (ICG) angiogram of the same area as Fig. 1 showing dark areas on angiography (straight arrow) that correspond to the birdshot lesions seen ophthalmoscopically. Typically these dark areas appeared to be bordered by large to mediumsized choroidal vessels and were occasionally seen to be traversed by small choroidal vessels (curved arrow). There was one area of ICG leakage seen nasal to the optic disc.

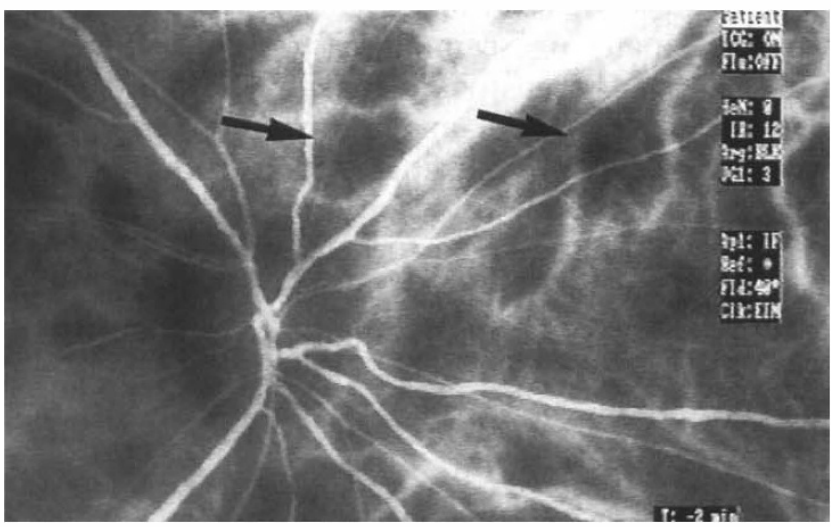

Fig. 4. Patient 2. ICG angiogram of the same area as Fig. 1 performed 5 months later at the same stage in the run as Fig. 2. The hypofluorescent areas persist (arrows) but there is no leakage of ICG.

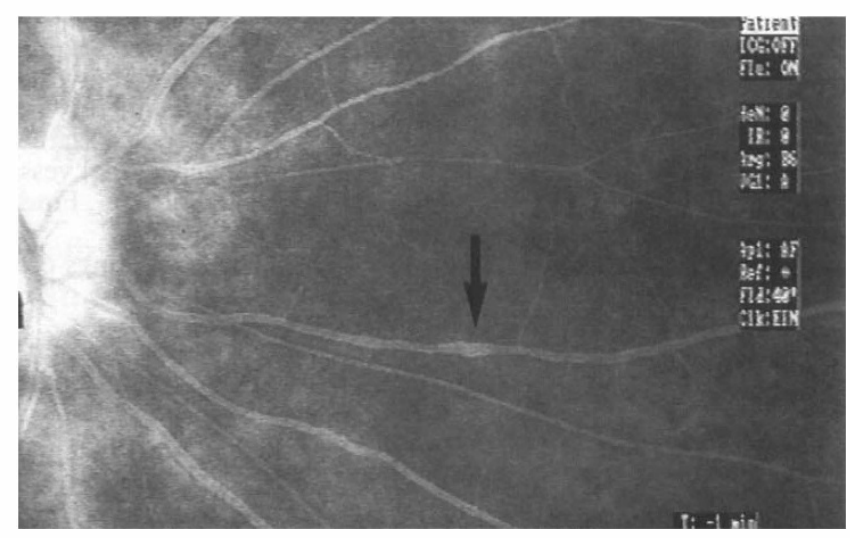

Fig. 5. Patient 2. Fluorescein angiogram of the same area as Fig. 1 performed on the scanning laser ophthalmoscope on the same day as Fig. 4. Area of fundus shown is just nasal to the optic disc. The birdshot lesions are not demonstrated. There is some fluorescein leakage from retinal veins (arrow) and from the optic disc. 


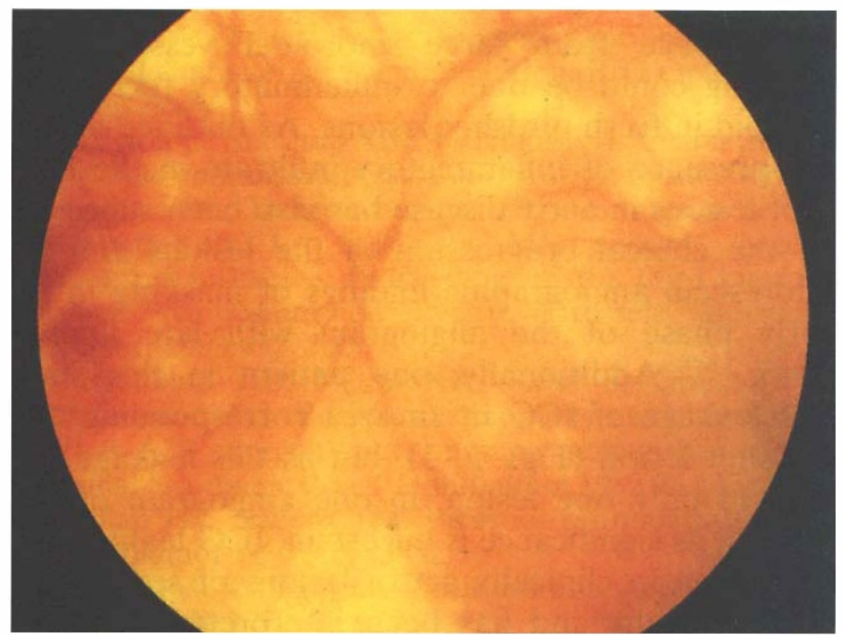

Fig. 6. Patient 3 (disease duration 3 years). Colour photograph of left eye showing marked yellow-white birdshot lesions. There is also swelling of the optic disc and disciform macular scarring.

who had had ocular symptoms for 6 years, did not exhibit any fluorescein leakage on angiography.

ICG angiography (Table II) demonstrated normal large choroidal vessels in all patients. In all cases the birdshot lesions were more evident on ICG angiography than fluorescein angiography (compare Figs. 4 and 5) and corresponded to hypofluorescent areas on the ICG angiograms (Figs. 2-4). Typically these dark areas appeared to be bordered by large to medium-sized choroidal vessels. These hypofluorescent areas could occasionally be seen to be traversed by smaller choroidal vessels (Figs. 2,7). The two patients ( 1 and 2 ) who had the shortest disease duration at the time of angiography also demonstrated the occasional hypofluorescent area on ICG angiography that masked fluorescence from underlying choroidal vessels. Patient 2 additionally demonstrated leakage of ICG from an area that corresponded to a birdshot lesion nasal to the right optic disc (Figs. 2, 3). This leakage of ICG was not present on repeat angiography 5 months later. In patients with disease duration of greater than 2 years, hypofluorescent areas that corresponded to the birdshot lesions were still discernible on ICG angiography but were relatively subtle in comparison with the striking clinical picture (compare Figs. 6 and 7).

\section{DISCUSSION}

The pathogenesis of birdshot chorioretinopathy remains speculative for a number of reasons. The rarity of this disease means it is difficult to obtain large numbers of patients for systematic clinical studies, while to date there has only been one pathological report of birdshot chorioretinopathy. ${ }^{4}$ Unfortunately the globe examined in this latter study had been phthisical for 2 years prior to enucleation,

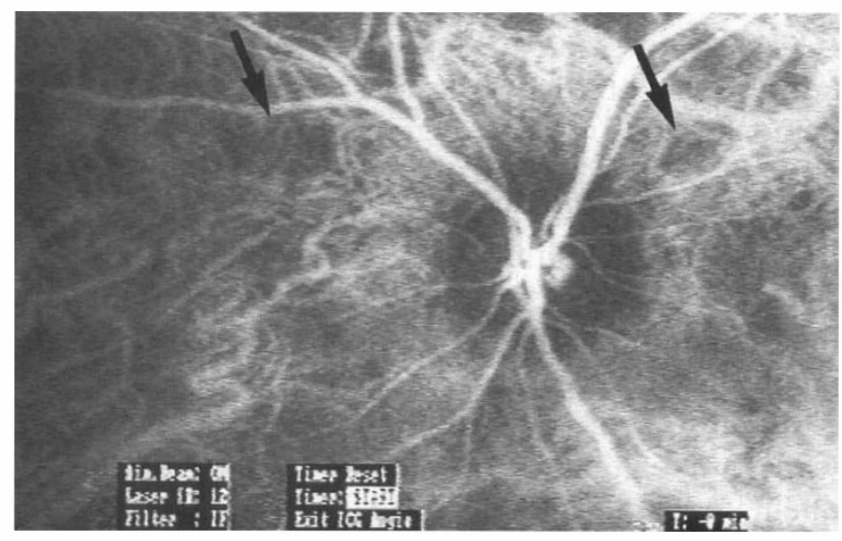

Fig. 7. Patient 3. ICG angiogram of the same area as Fig. 6. Faint areas of hypofluorescence that correspond to the birdshot lesions are seen (arrows).

making the findings of doubtful significance. The frequently insidious onset of ocular symptoms in birdshot chorioretinopathy makes it difficult to observe the full natural history of this condition and, in keeping with this observation, the earliest angiogram performed in this study was on a patient who had already had visual symptoms for 6 months.

The inflammatory nature of this condition is immediately apparent from the clinical picture, with vitritis and occasional anterior segment inflammation. $1,2,4,5$ Involvement of the ocular vessels is indicated by the frequent leakage from retinal vessels seen both clinically as cystoid macular oedema and on fluorescein angiography. ${ }^{1,2,4,5} \mathrm{Six}$ of the seven patients in this study demonstrated breakdown in the blood-retinal barrier manifest by fluorescein leakage on angiography (Table II). T lymphocyte involvement may be implicated by the strong association of birdshot chorioretinopathy with the major histocompatibility antigen HLA A $29^{11}$ (incidence of $80-96 \%$ compared with $7 \%$ in the control population ${ }^{4,7,12}$ ) and has suggested a rationale for treating these patients with cyclosporine. .,13,14 Sarcoidosis can present with an identical fundal appearance to birdshot chorioretinopathy ${ }^{10}$ providing further, circumstantial support for an inflammatory basis to this condition. The aetiology of the birdshot lesions themselves has been much debated. It has been suggested that they represent areas of hypopigmentation of the choroid ${ }^{6}$ or inflammatory foci that are associated with the choroidal veins. ${ }^{1,2}$ A number of studies have noted a tendency for the birdshot lesions to become increasingly white and atrophiclooking over time, ${ }^{2,6}$ which can be explained by either increasing choroidal depigmentation and/or localised choroidal atrophy secondary to inflammation.

The retinal abnormalities of birdshot chorioretinopathy were demonstrated most clearly in this study on FFA and were manifest as dye leakage from retinal capillaries, veins and optic discs (Table II). 
ICG was not seen to leak from the retinal vasculature. The birdshot lesions, in contrast, were demonstrated on ICG angiography but not seen at all with FFA in any of the patients studied. This is compatible with the lesions being located below the retinal pigment epithelium (RPE) within the choroid. The ICG angiographic findings were consistent with the ophthalmoscopic picture of widespread choroidal involvement in birdshot chorioretinopathy. This correlates with electrophysiological tests which, while not exhibiting diagnostic changes, show frequent, variable abnormalities in both the electrooculogram and electroretinogram, indicating the diffuse nature of this disease..$^{2,4,5,6}$ The ICG angiographic abnormalities seen here of dark areas that correspond to the birdshot lesions which are associated with large choroidal vessels also correlate with the clinical appearance of the lesions being associated with choroidal veins. The choroidal veins themselves appeared normal on ICG angiography in this study and it is unclear why such an association should exist.

The results outlined above agree with previous short reports of ICG angiography in birdshot chorioretinopathy, ${ }^{15-17}$ but these reports give no limited details of the angiographic findings. Hypofluorescent areas on ICG angiography have now been reported in a number of other conditions with a possible inflammatory aetiology including acute posterior multifocal placoid pigment epitheliopathy ${ }^{18-20}$ (APMMPE), serpiginous choroidopathy, ${ }^{21}$ punctate inner choroidopathy ${ }^{22}$ and multiple evanescent white dot syndrome. ${ }^{23}$ The question arises as to whether these hypofluorescent areas represent choroidal vascular insufficiency or inflammatory choroidal infiltrate (or a combination of the two). In this study the hypofluorescent areas were typically bordered by large or medium-sized choroidal vessels with the occasional small choroidal vessel traversing the area (Fig. 2). Detailed imaging of the choriocapillaris is currently outside the resolution of ICG angiography but normal choriocapillaris is seen as a diffuse background fluorescence, suggesting there may be localised areas of small choroidal vessel (probably choriocapillaris) hypoperfusion within the birdshot lesions. These ICG angiographic findings are most in keeping with those seen in the placoid lesions of APMPPE ${ }^{18-19}$ in which localised choriocapillaris loss has been demonstrated by image analysis in one study ${ }^{20}$ However, the placoid lesions of APMPPE are seen on FFA as areas of early hypofluorescence and late hyperfluorescence. It is difficult to explain why the birdshot lesions were not seen on FFA in this and other studies.

The two patients with disease of shortest duration also demonstrated occasional hypofluorescent areas on ICG angiography that masked the underlying fluorescence from large choroidal vessels. This masking could be due to inflammatory foci in the choroid in fresh birdshot lesions. As outlined above, the presence of inflammatory infiltrate in the birdshot lesions in early disease has also been suggested by the clinical progression of the lesions and the fluorescein angiographic findings of masking in the early phase of the angiogram with late fluorescence. $^{2,6,7}$ Additionally, one patient in this study had leakage of ICG in an area corresponding to a birdshot lesion (Figs. 2, 3), but as this leakage was seen in only one lesion, in one angiogram of one patient, its significance is uncertain. ICG leakage has been seen in clinically active lesions of serpiginous choroidopathy and has been interpreted as representing a marked increase in the normal choroidal permeability. ${ }^{21}$

In long-standing disease there was discrepancy between the marked appearance of the birdshot lesions on ophthalmoscopic examination and the subtlety of the corresponding hypofluorescent areas on ICG angiography (Figs. 6,7), i.e. the choroidal angioarchitecture appeared relatively preserved within the birdshot lesions. It is tempting but highly theoretical to speculate on the disease course of the birdshot lesions by extrapolating findings from one individual to another, but this suggests that there may be some re-perfusion of the small choroidal vessels with time. Experimentally induced localised choriocapillaris deficits have certainly been shown to regress by a process of recanalisation and neovascularisation, 24,25 while usually leaving a lasting reduction in choriocapillaris density in the affected area. This observation would explain the faint but persisting hypofluorescent areas (Fig. 7). Similar findings have also been seen in the resolved placoid lesions of APMPPE. ${ }^{18-20}$ A relatively normal choroidal angioarchitecture within the birdshot lesions in long-standing disease means that there must be another basis for their frequently striking clinical appearance. Gass' suggestion ${ }^{6}$ of focal depigmentation within the choroid due to localised melanocyte loss seems the most plausible. This is more probable than the alternative possibilities of changes within the RPE or Bruch's membrane as these would be readily detected on fluorescein angiography.

This study was supported by grants from The Research (Endowments) Fund of St Thomas' Hospital, London and The Iris Fund for the Prevention of Blindness, UK. We thank Hong Woon, FRCS, FRCOphth for performing some of the ICG angiograms.

Key words: Birdshot chorioretinopathy, Indocyanine green angiography, Fluorescein angiography, Uveitis.

\section{REFERENCES}

1. Ryan SJ, Maumenee AE. Birdshot chorioretinopathy. Am J Ophthalmol 1980;89:31-45. 
2. Priem HA, Oosterhuis JA. Birdshot chorioretinopathy: clinical characteristics and evolution. Br J Ophthalmol 1988;72:646-59.

3. Edelston C, Stanford MR, Graham EM. Evaluation of systemic immunosuppression in birdshot retinochoroidopathy. In: Dernouchamps JP, Verougstraete C, Caspers-Velu L, Tassignon MJ, editors. Recent advances in uveitis. Proceedings of the third international symposium on uveitis, Brussels, Belgium. Kugler, 1993:497-500.

4. Nussenblatt RB, Mittal KK, Ryan S, Green WR, Maumenee AE. Birdshot retinopathy associated with HLA-A29 antigen and immune responsiveness to retinal S-antigen. Am J Ophthalmol 1982;94:147-58.

5. Kaplan HJ, Aaberg TM. Birdshot retinopathy. Am J Ophthalmol 1980;90:773-82.

6. Gass JDM. Vitiliginous chorioretinitis. Arch Ophthalmol 1981;99:1778-87.

7. Vitale AT, Rodriguez A, Foster CS. Low-dose cyclosporine therapy in the treatment of birdshot retinochoroidopathy. Ophthalmology 1994;101:822-31.

8. Bischoff PM, Flower RW. Ten years experience with choroidal angiography using indocyanine green dye: a new routine examination or an epilogue? Doc Ophthalmol 1985;60:235-91.

9. Scheider A, Schroedel C. High resolution indocyanine green angiography with a scanning laser ophthalmoscope. Am J Ophthalmol 1989;108:458-9.

10. Brod RD. Presumed sarcoid choroidopathy mimicking birdshot retinochoroidopathy. Am J Ophthalmol 1990;109:357-8.

11. Feltkamp TEW. Ophthalmological significance of HLA associated uveitis. Eye 1990;4:839-44.

12. Priem HA, Kijlstra A, Noens L, Baarsma GS, De Laey JJ, Oosterhuis JA. HLA typing in birdshot chorioretinopathy. Am J Ophthalmol 1988;105:182-5.

13. Nussenblatt RB, Palestine AG, Chan CC. Cyclosporine A therapy in the treatment of intraocular inflammatory disease resistant to systemic corticosteroids and cytotoxic agents. Am J Ophthalmol 1983;96:275-82.

14. Le Hoang P, Girard B, Deray G, et al. Cyclosporine in the treatment of birdshot chorioretinopathy. Transplant Proc 1988;20(3 Suppl 4):128-30.
15. Yannuzi LA, Sorenson JA, Guyer DR, Slakter JS, Chang $\mathrm{B}$, Orlock $\mathrm{D}$. Indocyanine green videoangiography: current status. Eur J Ophthalmol 1994; 4:69-81.

16. Chang B, Goldstein DA, Rabb MF, Tessler HH, Slakter JS, Yannuzi LA. Indocyanine green angiographic features in birdshot retinochoroidopathy [abstract]. Invest Ophthalmol Vis Sci 1995;36:S782.

17. Herbort CP, Borruat F, de Couten C, Jaccard L. Angiographie au vert d'indocyanine dans les uvéites postérieures. Klin Monatsbl Augenheilkd 1996; 208:321-6.

18. Yuzawa M, Kawamura A, Matsui M. Indocyanine green video angiographic findings in acute posterior multifocal placoid pigment epitheliopathy. Acta Ophthalmol (Copenh) 1994;72:128-33.

19. Dhaliwhal RS, Maguire AM, Flower RW, Arribas NP. Acute posterior multifocal placoid pigment epitheliopathy: an indocyanine green angiographic study. Retina 1993;13:317-25.

20. Howe LJ, Woon H, Graham EM, Fitzke F, Bhandari A, Marshall M. Choroidal hypoperfusion in acute posterior multifocal placoid pigment epitheliopathy: an indocyanine green angiography study. Ophthalmology 1995;102:790-8.

21. Giovannini A, Mariotti C, Ripa E, Scassellati-Sforzolini B. Indocyanine green angiographic findings in serpiginous choroidopathy. Br J Ophthalmol 1996; 80:536-40.

22. Tiffin PAC, Maini R, Roxburgh STD, Ellingford A. Indocyanine green angiography in a case of punctate inner choroidopathy. Br J Ophthalmol 1996;80:90-1.

23. Ie D, Glaser BM, Murphy RP, Gordon LW, Sjaarda $\mathrm{RN}$, Thompson JT. Indocyanine green angiography in multiple evanescent white-dot syndrome. Am J Ophthalmol 1994;117:7-12.

24. Perry DD, Risco JM. Choroidal vascular repair after argon laser photocoagulation. Am J Ophthalmol 1982; 93:787-93.

25. Pollack A, Korte GE. Choroidal vascular repair: scanning and transmission electron microscopy. Experientia 1992;48:219-25. 